\title{
垂直磁気記録媒体としての無電解めつき コバルト合金磁性皮膜
}

逢坂哲彌*, 後藤文男 ${ }^{* *}$, 笠井直記 ${ }^{*}$, 菅沼葉二**

*早稻田大学理工学部応用化学科 (干160 新宿区大久保3-4-1)

** 日本電気株式会社基盤技術研究所（开213 川崎市高津区管崎4-1-1）

\section{1 緒言}

垂直磁気記録方式が従来の面内磁泀記録方式の記録密 度の限界を越える高密度磁気記録方侙として提案されて 以来 ${ }^{1}$, 垂直磁気記録に関して活発な研究がなされてい る. 垂直磁気記録媒体として最初に $\mathrm{Co}-\mathrm{Cr}$ スパッタ膜 が報告され ${ }^{1,2)}$ ，さらにいくつかの媒本が開発されている. 我々は大量生産性およびコスト面で大きい利点を持つ無 電解めっき法による媒体の開発を試々た。無電解 Co-P 皮膜に Mn を共析すると $\alpha$-Co の六方晶 $\mathrm{c}$ 軸が垂直に 配向し，この媒体として利用し得る问能性をすでに報告 したが゙゙ここの無電解Co合金膜の結晶構造抢よび磁気 特性を明らかにし，垂直磁気記録膜上して使用するに適 した皮膜作成条件をみいだし，さらに記録再生特性の検 討も行ったのでここに報告する。

\section{2 実験方法}

無電解めっきCo 合金皮膜は, アンモニアアルカリ性

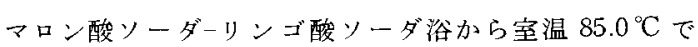
めっきした。 めっき用基板は $\mathrm{Cu}$ を用い, 最適条件付近 では研摩した無電解 $\mathrm{Ni}-\mathrm{P}$ を用いた. 皮膜の飽和磁化 $\mathrm{Ms}$ を低下させるため $\mathrm{Ni}$ を，また $\mathrm{c}$ 軸を垂值配向させるた め $\mathrm{Mn}$ 共析した. 皮膜の結晶構造汁 X線回折（Fe ター

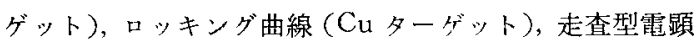
および組成分析から解析した。磁気特性は振動試料式磁 力計拉よびトルク測定計より決定した。記録再生試験は 8インチディスクを作成しリングへッドで行なった.

\section{3 結果と考察}

めっき浴中の $\mathrm{MnSO}_{4}$ 濃度を変化させた場合の無電 解 $\mathrm{Co}-\mathrm{Ni} \cdot \mathrm{Mn} \cdot \mathrm{P}$ 皮膜の代表的な X 線回折図を Fig. 1 に示した. $\mathrm{Co}(100)$ 面の回折ピーク性 $\mathrm{MnSO}_{4}$ 濃度の増 加に伴い消失し Co (002) 面の回折ビークが出現し，0.04 $\mathrm{M} の$ とき最も鋭い Co (002) ピーク方得られた. 従って, この条件のとき $\alpha-\operatorname{Co}$ 六方晶の $\mathrm{c}$ 軸が最も良好な垂㨁配 向性を示寸と考えられる。皮膜の組成分析結果からCo， $\mathrm{Ni}$ および $\mathrm{P}$ は $\mathrm{MnSO}_{4}$ 濃度には依存せず $\mathrm{Co}: \mathrm{Ni}=75: 20$ (重量比)の比を示し P は $3 \mathrm{wt} \%$ を含有している。 $\mathrm{Mn}$ は $0.02 \mathrm{M} \mathrm{MnSO}_{4}$ 濃度から微量に共析し徐々に増加がみ られる. $0.04 \mathrm{M}$ では $\mathrm{Mn} 1 \mathrm{wt} \%$ を含む. $\mathrm{MnSO}_{4}$ 濃度 が皮膜の垂直配向性に最も大きい影響を与えるが，浴中 $\mathrm{NiSO}_{4}$ 濃度㧍よび浴 $\mathrm{pH}$ も配向性を左右し最適 $\mathrm{pH}$

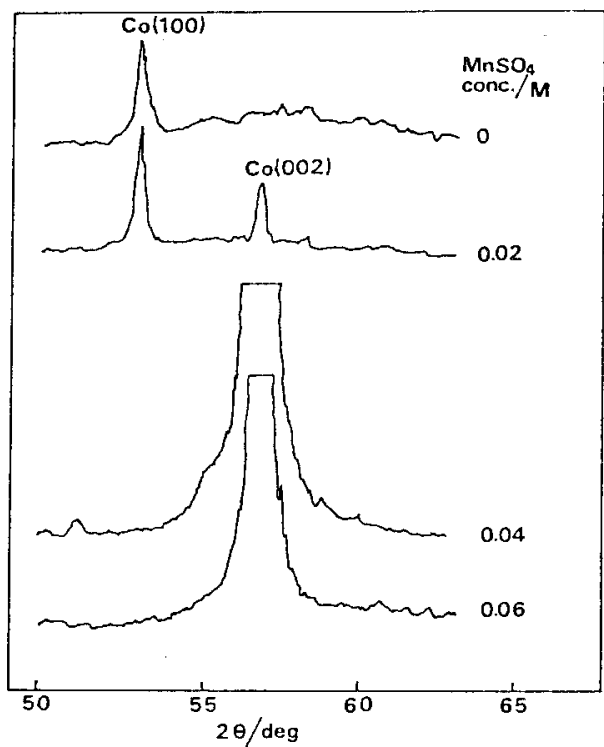

Fig. 1 X-ray diffraction patterns of the films with various $\mathrm{MnSO}_{4}$ concentration (using $\mathrm{Cu}$ substrate).
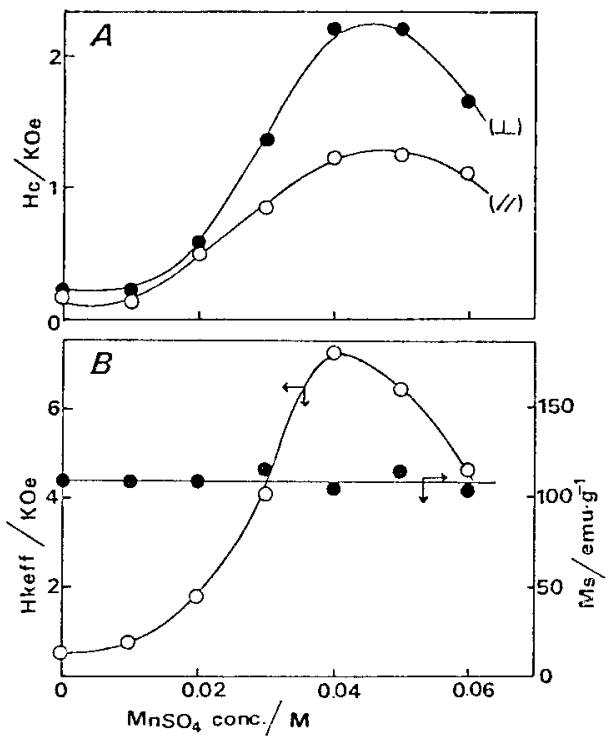

Fig.2 Effects of $\mathrm{MnSO}_{4}$ concentration on magnetic properties (Cu substrate). 


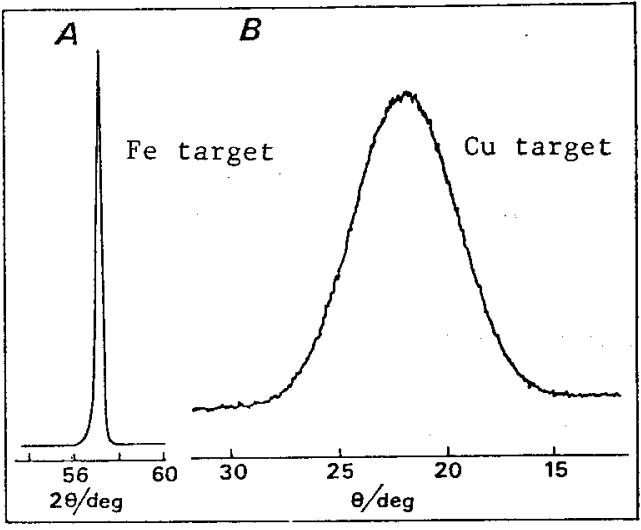

Fig.3 X-ray diffraction pattern and rocking curve of $\mathrm{Co}(002)$ ( $\mathrm{Ni}-\mathrm{P}$ substrate).

\section{6 であった。}

皮膜の磁気特性の $\mathrm{MnSO}_{4}$ 濃度依存性を Fig. 2 に示し た。保磁力 $\mathrm{Hc}$ 注磁界を垂直 $(\perp)$ 扩よび面内 ( / I ) 方向 こかけた場合を示しているが, $\mathrm{MnSO}_{4}$ 濃度が 0.04 0.05 $\mathrm{M}$ で両方向ともに最大值を示している. $\mathrm{Hc}$ 岋基板を $\mathrm{Cu}$ から Ni-P に変えると低下する傾向がみられ，熱処理に よりさらに低下させることができる. 皮膜の飽和磁化 Ms は $\mathrm{Ni}$ 共析により $110 \mathrm{emu} \cdot \mathrm{g}^{-1}$ を示すが, 結晶配向性を 保ちながら $90 \mathrm{emu} \cdot \mathrm{g}^{-1}$ 程度まで低下させることが可能 であった、トルク曲線から磁気異方性エネルギー Kuを を求めた結果 $\mathrm{Ku} \simeq 0$ であったが，完全な垂直磁化容易 状態を得るには Msがさらに低下することが必要である。 一方，垂直磁化容易性の目安となる Hkeff は $\mathrm{MnSO}_{4}$ 濃 度に強く依存し $0.04 \mathrm{M}$ で最大值 $7 \mathrm{kOe}(\mathrm{Ni}-\mathrm{P}$ 基板では $8 \mathrm{kOe}$ となる)を示し，Fig. 1 の結晶構造とのよい相関 性を示吉。 $\mathrm{Cu}$ 基板から $\mathrm{Ni}-\mathrm{P}$ 基板に変え最適条件で皮 膜を作成した場合，その皮膜のロッキング曲線 (Fig. 3) は半值幅角度 $\Delta \theta_{50}=5.7^{\circ}$ t示し, $\mathrm{c}$ 軸は分散度の非常に 低い垂直配向上なっていることが認められた。

Fig. 4 に皮膜断面のSEM 写真を示したが，六方晶格 子が垂直方向に生長し柱状構造を形成している. みかけ 上 $0.2 \mu \mathrm{m}$ 程度の柱状結晶であるが, 10000 倍 $\mathrm{SEM}$ 写 真では， $0.2 \mu \mathrm{m}$ 柱状構造が $0.05 \mu \mathrm{m}$ 程度の細かい柱状結 晶から形成されていることが認められた. 従って，この めっき皮膜は垂直磁気記録に適した結晶構造を形成して いると考えられる.

実際の記録再生試験は 8 インチディスクを作成しリン グへッドで行なった．この時のディスクおよびヘッド特 性をTable 1 に示した. ディスク回転数は $3000 \mathrm{rpm}$ で ある、垂直磁気記録に括いて低密度記録では出力波形に ダイパルス (dipulse)を生じることが認められている Fig. 5 は $740 \mathrm{FRPI}(0.32 \mathrm{MHz})$ 低密度記録を行なった時 の出力波形を示すがここれは明らかにダイパルス波形を

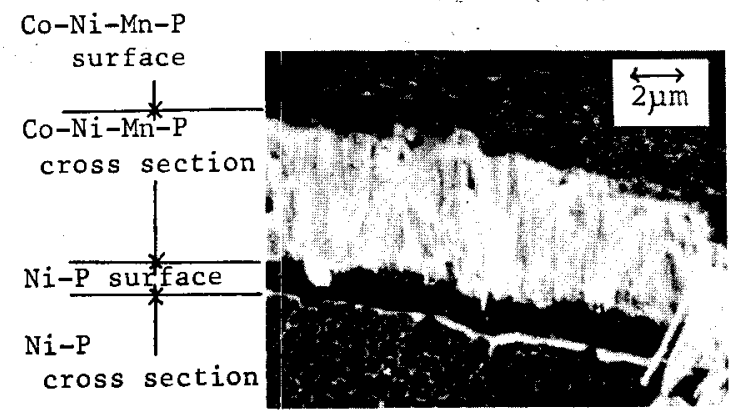

Fig.4 SEM photograph of film structure.

Table 1 Characteristics of disk and head

\begin{tabular}{ll} 
Medium material & Co-Ni-Mn-P \\
Medium thickness & $5.0 \mu \mathrm{m}$ \\
Coercivity (Hc $\perp$ ) & $1,100 \mathrm{oe}$ \\
Overcoat thickness & $0.1 \mu \mathrm{m}$ \\
Substrate material & polished $\mathrm{Ni}-\mathrm{P}$ on \\
& aluminum alloy \\
Core material & Mn-zn ferrite \\
Gap length & $1.0 \mu \mathrm{m}$ \\
Track width & $50 \mu \mathrm{m}$ \\
Flying height. & $0.2 \mu \mathrm{m}$ at $22 \mathrm{~m} / \mathrm{s}$ \\
\hline
\end{tabular}

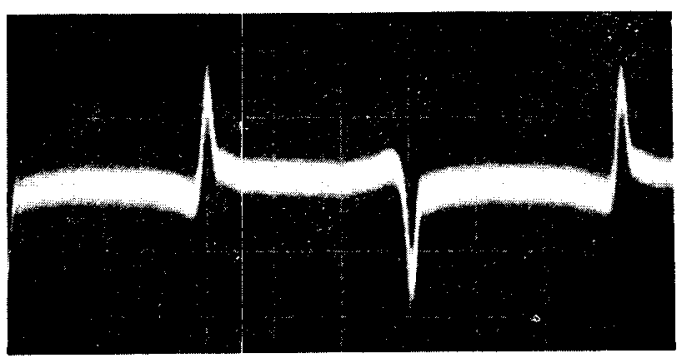

Fig.5 Reproduced waveform at low density (740 FRPI).

示している.このにとは，垂直記録がめっき磁性膜で行 なわれていること意味しているであろう．以上より無 電解めっき $\mathrm{Ca}-\mathrm{Ni}-\mathrm{Mn}-\mathrm{P}$ 皮膜は垂值磁気記録媒体とし て利用することが可能であると結論づけられるであるう。

本研究を行なうに当りご協力を頂いた早稲田大学小岩 一郎氏, 日本電気 (株) 柳沢雅広, 田中英男, 青山森繁 各氏に深謝いたします。

\section{文献}

1) S. Iwasaki and Nakamura, IEEE Trans. on Mag., MAG-13, 1272 (1977); S. Iwasaki, ibid., MAG-16, 71 (1980).

2) S. Iwasaki and K. Ouchi, ibid., MAG-14, 849 (1978).

3) 逢坂哲弥, 笠井直記, 後藤文男, 伊東由夫, 金属 表面技術第 63 回大会要旨集, p. 56 (1981).

4) 岩崎俊一, 鈴木俊行, 昭 55 電子通信学会全国大 会要旨集 p. 199 (1980).

(Received Sef. 28, 1981 ; Accepted Oct. 7, 1981) 